\title{
Avaliação de projeções climáticas para uma bacia experimental, localizada na região sul de Minas Gerais
}

As mudanças climáticas no século XXI é uma realidade inconteste. Diversos efeitos e impactos vêm sendo registrados sobre o clima e, como consequência, sobre a sociedade em várias regiões do planeta. Eventos extremos cada vez mais severos estão sendo observados, destacando-se secas extremas e chuvas intensas, poucas vezes registradas no passado. O que possibilitou estudos envolvendo mudanças no clima foi à alta performance dos modelos climáticos disponíveis, que simulam as propriedades dinâmicas da atmosfera com uma precisão aceitável. Tal processo acarreta a presença de erros sistemáticos nas saídas dos modelos climáticos, devido a imperfeição ao discretizar os processos que ocorrem na atmosfera. Mediante estas questões, o objetivo deste trabalho consiste em aplicar a técnica de correção de erros sistemáticos percentil por percentil, realizada para a precipitação total e a temperatura média da estação meteorológica da Bacia Hidrográfica do Ribeirão Jaguara (BHRJ), localizada em Minas Gerais e, posteriormente, verificar a tendência da precipitação total e temperatura média ao longo do século utilizando diferentes cenários. Para tal análise, utilizou-se as projeções oriundas dos modelos climáticos Eta-HadGEM2-ES, Eta-MIROC5 e Eta-CanESM2, sob os cenários RCP4.5 e RCP8.5. Os resultados mensais das variáveis, projetados pelos três modelos, sugerem que foi possível capturar os padrões de variações mensal até o final do século XXI (2006-2099), com cenários RCP4.5 e RCP8.5, quando comparados aos resultados do clima presente (1961-2005).

Palavras-chave: Mudanças climáticas; Modelos climáticos; Correção de erros sistemáticos.

\section{Evaluation of the climatic forecast for an experimental basin, located in the southern region of Minas Gerais}

Climate change in the 21st century is an indisputable reality. Effects and impacts have been recorded on the climate and society in many regions of the planet More and more severe extreme events are being observed, especially extreme droughts and heavy rainfall, rarely recorded in the past. What made the studies involving changes in climate possible was the high performance of the available climate models, which simulate the dynamic properties of the atmosphere with acceptable precision. Such a process leads to the presence of systematic errors in the outputs of climate models, due to the imperfection in distinguishing the processes that occur in the atmosphere. With these questions, the objective of this work is to evaluate the bias correction technique percentile by percentile, performed for the precipitation and the temperature of the meteorological station of the Jaguara Creek basin, located in Minas Gerais and verify the trend of total precipitation and average temperature over the century using different scenarios. For this analysis, the projections of the Eta-HadGEM2-ES, Eta-MIROC5 and EtaCanESM2 climate models were used, under the scenarios RCP4.5 and RCP8.5. The monthly results projected by the three models suggest that it was possible to capture the patterns of monthly variations until the end of the 21st century (2006-2099), with the scenarios RCP4.5 and RCP8.5, when compared to baseline period (1961-2005).

Keywords: Climate change; Climate models; Correction of systematic errors.

Topic: Meteorologia, Climatologia e Mudanças Climáticas

Reviewed anonymously in the process of blind peer.

Estefânia Maria Sousa Zákhia (iD)

Universidade Federal de Lavras, Brasil

http://lattes.cnpq.br/3426875273811043

http://orcid.org/0000-0002-0301-119X

estefania.zakhia@estudante.ufla.br

Lívia Alves Alvarenga

Universidade Federal de Lavras, Brasil

http://lattes.cnpq.br/8014126811283124

http://orcid.org/0000-0002-2291-7966

livia.aalvarenga@ufla.br

Javier Tomasella (iD)

Centro Nacional de Monitoramento e Alertas de Desastres Naturais, Brasil http://lattes.cnpq.br/7168284647925847

http://orcid.org/0000-0003-2597-8833

javier.tomasella@cemaden.gov.br
Received: 02/10/2020

Approved: $24 / 11 / 2020$

Minella Alves Martins

Centro Nacional de Monitoramento e Alertas de Desastres Naturais, Brasi http://lattes.cnpq.br/0135992350127405

http://orcid.org/0000-0002-6856-692X

minella.martins@cemaden.gov.br
Referencing this:

ZÁKHIA, E. M. S.; ALVARENGA, L. A.; TOMASELLA, J.; MARTINS, M. A. Avaliação de projeções climáticas para uma bacia experimental, localizada na região sul de Minas Gerais. Revista Ibero Americana de Ciências Ambientais, v.11, n.6, p.234-250, 2020. DOI: http://doi.org/10.6008/CBPC2179-6858.2020.006.0020 


\section{INTRODUÇÃO}

A problemática envolvendo as mudanças climáticas retrata um dos maiores desafios para a humanidade no decorrer do século XXI. Conforme abordado pelo Painel Intergovernamental sobre Mudanças Climáticas (IPCC, 2013), as mudanças no clima podem aumentar a frequência e a intensidade de eventos climáticos extremos. Além disso, podem afetar a duração dos períodos de estiagem e a magnitude das enchentes, além de outras consequências, como o decaimento da produção agrícola, disseminação de doenças e significativas alterações na disponibilidade hídrica em diversas regiões (CASAGRANDE et al., 2017; SIQUEIRA JÚNIOR et al., 2015; LELIS et al., 2011; MARTINS et al., 2018; MARTINS et al., 2019).

Os modelos climáticos tornaram-se a mais valiosa ferramenta científica disponível atualmente para auxiliar possíveis mudanças nos padrões climáticos do planeta (MELLO et al., 2015). Os modelos climáticos podem ser subdivididos em modelos climáticos globais (MCGs), que possuem resolução espacial horizontal de centenas de quilômetros e modelos climáticos regionais (MCRs), que possuem um domínio limitado e resolução espacial na ordem de dezenas de quilômetros, permitindo detalhar nossos cenários climáticos resultantes dos MCGs incluindo aspectos como topografia, vegetação heterogênea, dentre outros (SALES et al., 2015). Além disso, os MCRs também são responsáveis pela técnica de regionalização (downscaling) dos resultados advindos de MCGs. Essa é a técnica mais viável para escalonar as variáveis de baixa resolução espacial dos modelos globais para escalas locais mais refinadas. Nela, os modelos regionais adotam como condições de contorno nas laterais do domínio geográfico os dados provenientes dos modelos climáticos globais (OLIVEIRA et al., 2017; SAMPAIO et al., 2014).

A sensibilidade da hidrologia em escala regional a condições climáticas variáveis faz com que as projeções de mudanças climáticas sejam essenciais para avaliar variações futuras no ciclo hidrológico. 0 método mais comum para estimar os impactos de mudanças climáticas na hidrologia envolve variáveis meteorológicas (por exemplo, temperatura, precipitação, umidade relativa do ar etc.) de modelos climáticos globais (MCGs) combinados com modelos hidrológicos. No entanto, para estudos que visam avaliar o impacto regional, a resolução grosseira dos MCGs (100 - $250 \mathrm{~km}$ ) é inadequada, pois faltam informações detalhadas na representação da topografia e uso e ocupação do solo, por exemplo (TEUTSCHBEIN et al., 2012).

Nesse contexto, erros sistemáticos, comumente chamados de bias, são esperados nas saídas dos modelos climáticos, devido à imperfeita conceituação e discretização dos processos que ocorrem na atmosfera. Dentre os principais erros sistemáticos dos modelos climáticos, pode-se elencar a ocorrência de muitos dias de precipitação de baixa intensidade e estimativa incorreta de temperaturas extremas, além da subestimação, superestimação e variações sazonais incorretas da precipitação. Portanto, o uso de saídas de modelos climáticos regionais não corrigidas como entradas em modelos hidrológicos conduzirá a uma avaliação não realista das condições hidrológicas, principalmente sob condições de mudanças climáticas, onde o tempo de integração é mais longo (MARTINS et al., 2019; TEUTSCHBEIN et al., 2012).

As mudanças climáticas envolvem interações complexas em escala global que impactam o balanço de água e energia em escalas menores. Os efeitos das mudanças climáticas nos recursos hídricos já foram 
estudados utilizando os cenários do IPCC na região do Alto Rio Grande, a qual encontra-se a sul do estado de Minas Gerais (MELLO et al., 2015; OLIVEIRA et al., 2017; VIOLA et al., 2015). No entanto, tais efeitos podem ser melhor avaliados em bacias de pequeno porte, sendo possível inferir sobre os impactos das mudanças climáticas no cotidiano daqueles que utilizam os recursos hídricos para diferentes atividades na região. Nesse caso, optou-se por avaliar as projeções climáticas na Bacia Hidrográfica do Ribeirão Jaguara (BHRJ), localizada na região Alto do Rio Grande, por tratar-se de uma bacia de pequeno porte $\left(33 \mathrm{~km}^{2}\right)$ representativa de Latossolos e uso dos solos típicos desta região, a qual vem sendo severamente degradada ao longo dos últimos anos (ALVES et al., 2019).

Existem diversas técnicas de correção para extinguir erros sistemáticos. No presente estudo, o objetivo foi utilizar a abordagem percentil por percentil, para corrigir erros sistemáticos da precipitação diária e da temperatura média diária das projeções climáticas referentes a um único ponto na Bacia Hidrográfica do Ribeirão Jaguara (BHRJ). Para isso, serão utilizadas projeções de três modelos climáticos (CanESM2, HadGEM2-ES, MIROC5), regionalizados pelo modelo Eta, sob condições dos cenários RCP4.5 e RCP8.5, advindos do Quinto Relatório de Avaliação (AR5), do IPCC (CHOU et al., 2014a; CHOU et al., 2014b; LYRA et al., 2018). Estudos sobre mudanças climáticas e seus impactos nos recursos hídricos já foram realizados na região do Alto Rio Grande. No entanto, esta é a primeira vez que resultados sobre projeções mensais e sazonais de precipitação e temperatura são analisados, utilizando o RCP4.5 e RCP8.5, para auxiliar em outras pesquisas na BHRJ.

\section{METODOLOGIA}

\section{Área de estudo}

A Bacia Hidrográfica do Ribeirão Jaguara (BHRJ), localizada entre as coordenadas geográficas -

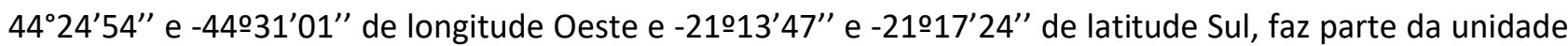
geomorfológica do Planalto Campos das Vertentes, na Região do Alto Rio Grande e Unidade de Planejamento e Gestão dos Recursos Hídricos GD1, no estado de Minas Gerais, a sudeste do Brasil (Figura 1).

A BHRJ possui uma área de drenagem de $33 \mathrm{~km}^{2}$ e deságua diretamente no reservatório da Usina Hidrelétrica de Camargos (UHE), pertencente a Companhia Energética de Minas Gerais (CEMIG). Diversos estudos (ALVES et al., 2019; ANDRADE et al., 2012; BESKOW et al., 2011b; BESKOW et al., 2011a) destacam que o comportamento dessa bacia é relevante na compreensão da dinâmica do ciclo hidrológico e no auxílio à tomada de decisões na referente região, no que diz respeito ao uso, conservação e preservação da qualidade dos recursos naturais, visto que há um avançado estágio de degradação destes.

O clima na BHRJ, conforme a classificação Köppen, é do tipo Cwa e caracteriza-se por verões quentes e úmidos e invernos frios e secos. A temperatura e precipitação média anual são de 19 ㄷ e 1500 mm, respectivamente (ALVES et al., 2019; ANDRADE et al., 2012; MELLO et al., 2012). 

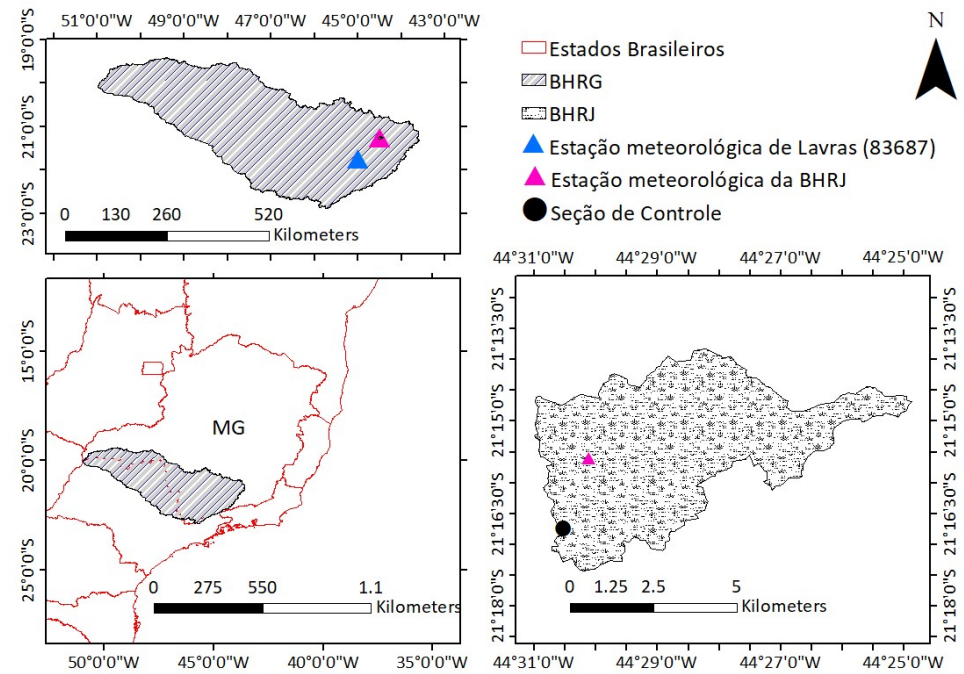

Figura 1: Localização da Bacia Hidrográfica do Ribeirão Jaguara na Bacia Hidrográfica do Rio Grande, na região sul do estado de Minas Gerais-MG.

No que diz respeito ao uso e ocupação do solo, foram identificados na BHRJ os seguintes usos: pastagem (38,5\%); culturas anuais, principalmente milho (Zea mays L.) e trigo (Triticum aestivum L.) (30,9\%); floresta nativa (15,1\%); eucalipto (Eucalyptus globulus) (10,3\%); solo nu (4,9\%); e área urbana (0,3\%). Quanto as classes de solos, aponta-se a predominância de Latossolos (53,6\%), solos argilosos, profundos e com alta porosidade. Também é possível encontrar em porcentagens menores Cambissolo háplico distrófico típico $(19,3 \%)$ e Neossolo flúvico $(27,1 \%)$ (ALVES et al., 2019). A bacia possui variação de altitude de 949 e 1084 metros, sendo a elevação média da bacia de 998 metros e a sua declividade média de $13 \%$.

\section{Dados de entrada}

Nesse estudo foram utilizadas as seguintes bases de dados: série de precipitação total e temperatura média diárias da estação meteorológica localizada na BHRJ (Figura 1), no período de 2006-2014; série de precipitação total e temperatura média diárias da estação meteorológica automática de Lavras (código 83687), pertencente ao Instituto Nacional de Meteorologia (INMET), no período de 1961-2014; projeções climáticas diárias da precipitação total e da temperatura média interpoladas para o ponto de grade da BHRJ, as quais foram extraídas da Plataforma de Projeções de Mudança do Clima para a América do Sul regionalizadas pelo modelo Eta (PROJETA), pertencente ao Centro de Previsão de Tempo e Estudos Climáticos (CPTEC), do Instituto Nacional de Pesquisas Espaciais (INPE). Foram obtidas as projeções para o clima presente (1961-2005) e para o clima futuro (2006-2099), sob os cenários RCP4.5 e RCP8.5, por meio da simulação climática dos modelos Eta-MIROC5, Eta-HadGEM2-ES e Eta-CanESM2, com resolução horizontal de $20 \mathrm{~km}$

\section{Modelos climáticos}

Dentre os inúmeros avanços científicos ocorridos nos últimos anos, destaca-se a habilidade em simular sistemas físicos de alta complexidade com o auxílio de modelos numéricos que são constituídos por representações matemáticas que se aproximam da realidade. Os modelos climáticos possibilitam a previsão 
das condições do tempo para dias consecutivos e também possuem a habilidade de projetar o clima na próxima estação ou simular características gerais do clima futuro, para décadas ou séculos, levando em consideração as modificações antropogênicas, como o aumento de emissão de gases de efeito estufa, aerossóis e as mudanças no uso e ocupação do solo (SAMPAIO et al., 2014).

Diversos MCGs foram disponibilizados no Coupled Model Intercomparison Project Phase 5 (CMIP5), entretanto, neste trabalho, foram utilizados apenas três deles: HadGEM2-ES, MIROC5 e CanESM2 (Tabela 1). Esses modelos foram avaliados e selecionados, dentre os mais de 40 modelos climáticos disponibilizados pelo CMIP5, por apresentarem melhor desempenho para simular o clima da América do Sul (CHOU et al., 2014a; CHOU et al., 2014b; LYRA et al., 2018). Além disso, ressalta-se a facilidade de acesso as projeções do CPTEC/INPE por meio da plataforma PROJETA e a fato destes modelos terem sido aplicados anteriormente em muitos estudos envolvendo mudanças climáticas (ALVARENGA et al., 2018; AMORIM et al., 2019; GU et al., 2018).

Tabela 1: Detalhamento dos modelos climáticos globais utilizados no presente estudo.

\begin{tabular}{|c|c|c|c|c|}
\hline \multirow[b]{2}{*}{ Abreviação } & \multirow[b]{2}{*}{ Nome do modelo } & \multicolumn{2}{|c|}{ Período de simulação } & \multirow[b]{2}{*}{ Referências } \\
\hline & & $\begin{array}{c}\text { Clima } \\
\text { presente }\end{array}$ & Projeções & \\
\hline $\begin{array}{l}\text { HadGEM2- } \\
\text { ES }\end{array}$ & $\begin{array}{l}\text { Hadley Centre Global Environmental Model 2- } \\
\text { Earth System }\end{array}$ & $1950-2005$ & $\begin{array}{l}2006- \\
2300\end{array}$ & $\begin{array}{l}\text { (COLLINS et al., 2011; JONES et } \\
\text { al., 2011) }\end{array}$ \\
\hline MIROC5 & $\begin{array}{l}\text { Model for Interdisciplinary Research on } \\
\text { Climate }\end{array}$ & $1950-2005$ & $\begin{array}{l}2006- \\
2100\end{array}$ & (WATANABE et al., 2010) \\
\hline CanESM2 & Canadian Earth System Model version 2 & $1850-2005$ & $\begin{array}{l}2006- \\
2100\end{array}$ & $\begin{array}{l}\text { (ARORA et al., 2011; CHYLEK et } \\
\text { al., 2011) }\end{array}$ \\
\hline
\end{tabular}

Fonte: Adaptado de Siqueira Júnior et al. (2015).

O MCR adotado para downscaling dos dados simulados do referente estudo é o modelo Eta (BLACK, 1994; MESINGER et al., 2012). O modelo Eta foi desenvolvido na Universidade de Belgrado e o Instituto de Hidrometeorologia da Iugoslávia, sendo, posteriormente, operacionalizado pelo National Centers for Environmental Prediction (NCEP). No Brasil, o modelo Eta foi instalado no CPTEC para previsões de curto prazo desde 1996 (MESINGER et al., 2012), para previsões sazonais desde 2002 (CHOU et al., 2014a) e para auxiliar estudos relacionados a mudanças climáticas (CHOU et al., 2014b), tendo como domínio a América do Sul e América Central (MARTINS et al., 2019).

\section{Projeções das mudanças climáticas}

O Quinto Relatório de Avaliação (AR5) (IPCC, 2013) forneceu projeções climáticas para quatro cenários ou quatro forçantes radiativas antropogênicas totais até o final do século XXI, denominados Representative Concentration Pathways (RCP) (em português, Caminhos Representativos de Concentração): RCP3-PD, RCP4.5, RCP6 e RCP8.5 $\mathrm{Wm}^{-2}$.

Estes cenários foram utilizados para as simulações com modelos climáticos realizadas no CMIP5. Os cenários incluem séries temporais de emissões e concentrações do conjunto completo de gases de efeito estufa e aerossóis e gases quimicamente ativos, bem como uso e ocupação do solo para cada um destes.

As projeções climáticas diárias utilizadas no presente estudo foram regionalizadas pelo modelo Eta, 
o qual consegue cobrir a maior parte da América do Sul e dos oceanos adjacentes a esse continente. Essas projeções foram escolhidas devido a disponibilidade dos dados e, também, para atender o objetivo do presente estudo. Conforme destacado por Chou et al. (2014b), os processos convectivos do modelo Eta ocorrem conforme o esquema de Betts-Miller (JANJIC, 1994) e o processo de precipitação é resolvido pelo esquema de Zhao (ZHAO et al., 1997). O modelo também conta com simulações de radiação de onda curta (LACIS et al., 1974) e onda longa (FELS et al., 1975). As condições de contorno lateral são extraídas do Modelo de Circulação Global do CPTEC (CAVALCANTI et al., 2002) e os processos de superfície são representados pelo modelo Noah (EK et al., 2003).

Foram consideradas os dois cenários AR5 do IPCC: o RCP4.5, que é intermediário e representa um aquecimento global médio para o final do século XXI variando entre 1,1 e 2,6 ํ e o RCP8.5, que representa o cenário mais pessimista e resulta num aquecimento médio variando entre 2,6 e 4,8 ㄷ (SANTOS et al., 2019).

\section{Correção de erros sistemáticos das projeções climáticas}

Na técnica proposta por Bárdossy et al. (2011) são geradas funções de probabilidade cumulativas (FDPs) para cada variável meteorológica corrigida para o ponto de grade em questão e para todo o período de observação. Esse método assume que os erros sistemáticos são determinados pelo deslocamento das funções de distribuição de probabilidade para o mesmo nível de frequência empírica (MARTINS et al., 2018). Portanto, para cada valor de grade das variáveis meteorológicas para o período de 1961-2005 produzido pelo modelo, foi determinada a probabilidade associada a esse valor usando a função de distribuição de frequência empírica. Para o mesmo nível de probabilidade, o valor corrigido de cada variável foi determinado por meio da função de distribuição empírica extraída dos dados observados em grade (SIQUEIRA JÚNIOR et al., 2015).

Conforme descrito por Martins et al. (2018; 2019) e Bárdossy et al. (2011), a Figura 2 ilustra um exemplo do procedimento de correção de erros sistemáticos da precipitação. A linha preta contínua representa as probabilidades de não excedência das precipitações projetada pelo modelo Eta para 2006. Já a linha cinza contínua representa as probabilidades de não excedência associadas às precipitações para o período de controle (1961-2005). Por exemplo, tem-se para um determinado mês uma precipitação prevista para o período de avaliação (2006) de 100 mm, com probabilidade de excedência de 0,7 (círculo sólido preto). Posteriormente, obtém-se a probabilidade referente à mesma precipitação na função ajustada aos dados observados no período de controle (1961-2005) (círculo sólido cinza). Em seguida, obtém-se para esta última probabilidade o valor de precipitação correspondente na função ajustada aos dados observados no mesmo período (1961-2005), fazendo com que esse valor de precipitação venha a ser adotado para a série corrigida do modelo. Por fim, esse valor de precipitação é adotado para a série corrigida do modelo Eta (período de avaliação), como ilustrado pelo círculo sólido cinza. Dessa forma, é possível constatar que o ano de avaliação (2006) foi retirado do período de controle (1961-2005) e assim se repete para os demais anos a serem avaliados e corrigidos. 


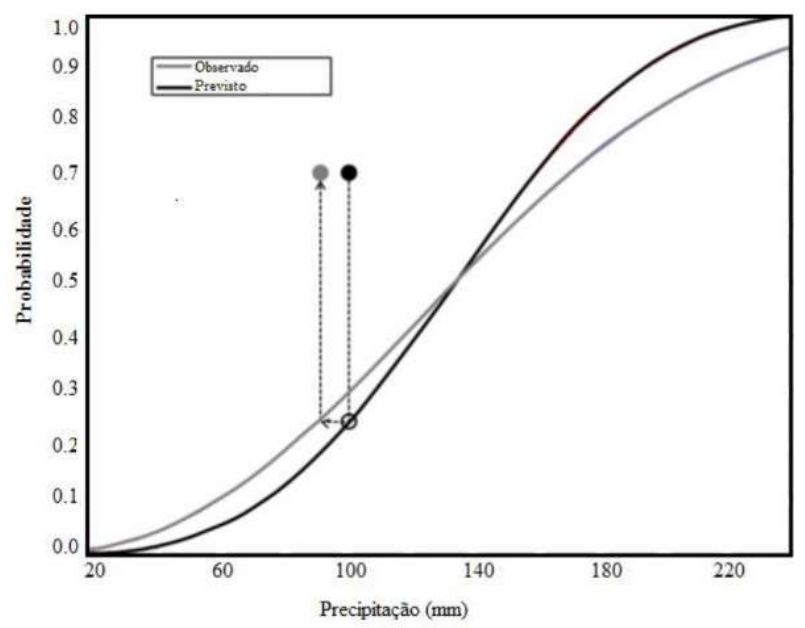

Figura 2: Esquema de representação da correção de erros sistemáticos do modelo Eta para a precipitação. Fonte: Adaptado de Martins (2017).

(a)

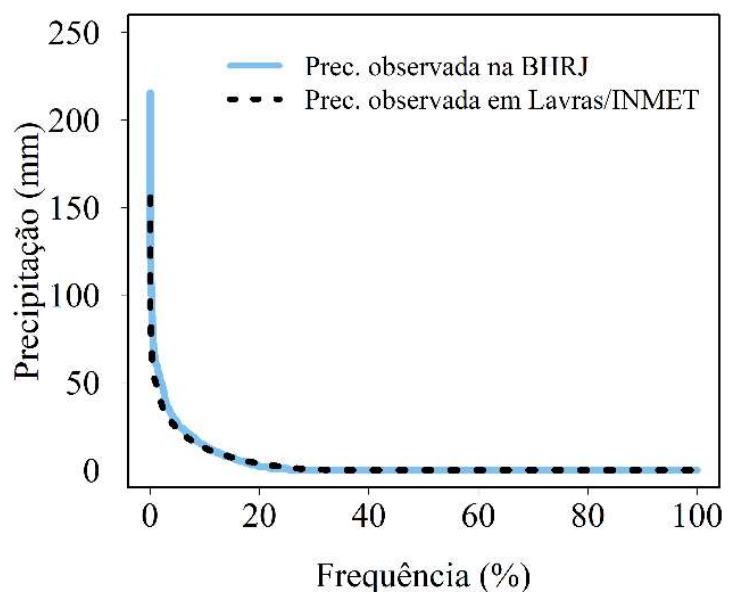

(c)

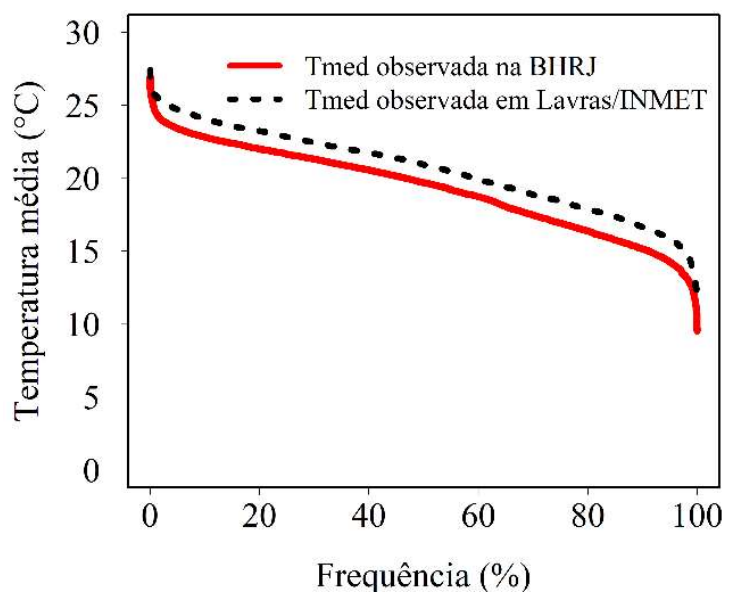

(b)

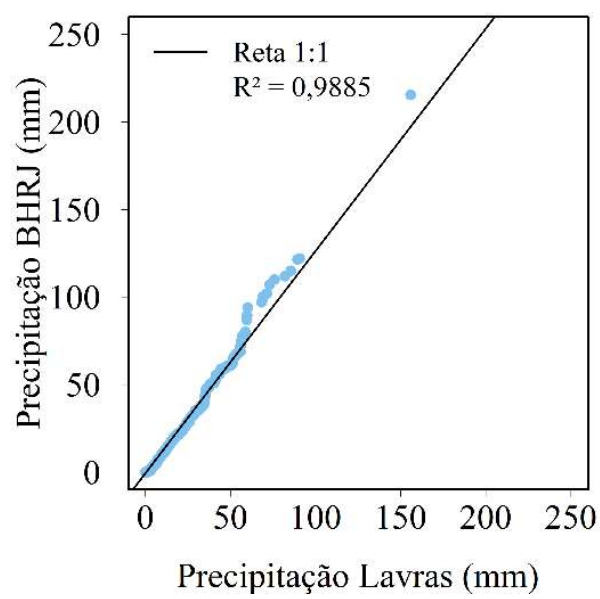

(d)

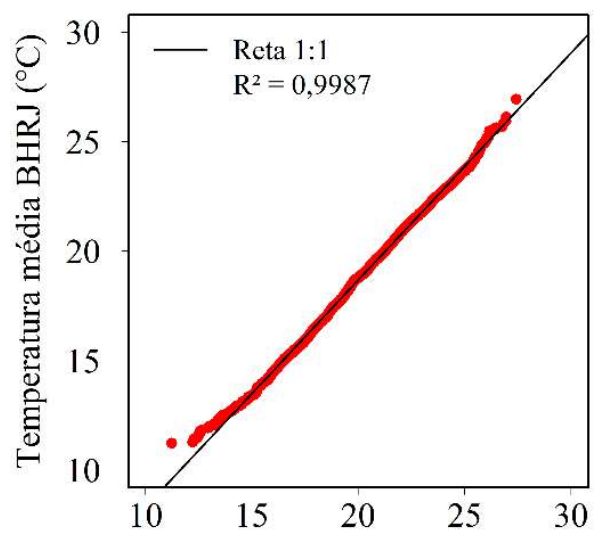

Temperatura média Lavras $\left({ }^{\circ} \mathrm{C}\right)$

Figura 3: Distribuição da frequência de excedência da precipitação total (Prec) (a) e da temperatura média (Tmed) (c) da estação meteorológica de Lavras/INMET e da estação meteorológica da BHRJ, no período de 2006-2014. A verificação de homogeneidade da precipitação total (b) e temperatura média (d) de ambas as estações, para o mesmo período, também foi apresentada.

As projeções da precipitação e da temperatura foram extraídas para o ponto de grade referente à localização da estação meteorológica da BHRJ na plataforma PROJETA, do CPTEC. As simulações feitas para o clima presente (1961-2005) e para o futuro (2006-2099), por meio dos modelos regionalizados Eta-MIROC5, Eta-HadGEM2-ES e Eta-CanESM2, foram corrigidas utilizando-se a série histórica de dados meteorológicos observada de Lavras (83687), pertencente ao Instituto Nacional de Meteorologia (INMET). A utilização da 
série histórica de dados observados de Lavras foi necessária devido à série de dados advinda da estação meteorológica da BHRJ apresentar dados somente de 2006 a 2014. Portanto, não há dados para comparação com o clima presente dos modelos climáticos regionais na BHRJ (1961-2005).

A comparação entre a série de dados meteorológicos de Lavras e da BHRJ foi feita por meio da distribuição de frequência de excedência da precipitação total (Figura 3a) e da temperatura média (Figura 3c), para o período de 2006 a 2014. Também foi possível observar a semelhança no regime de chuvas e da temperatura entre as duas estações, por meio de um ajuste linear, corroborando que os valores provenientes da estação meteorológica de Lavras podem ser utilizados na correção de erros sistemáticos das projeções do clima presente (1961-2005) dos modelos climáticos regionais, para um único ponto de grade da BHRJ. Verificou-se também que o ajuste linear de ambas as variáveis (Figura 3b e 3d) retornam um coeficiente de determinação próximos ao valor máximo (um), o que indica que, para o período de 2006-2014, a precipitação total e a temperatura média da estação meteorológica de Lavras possuem um bom ajuste em relação à precipitação total diária e a temperatura média diária da estação meteorológica da BHRJ, indicando homogeneidade destas variáveis.

\section{RESULTADOS}

As Figuras 4 e 5 mostram no clima presente (1961-2005) as simulações da precipitação total mensal e temperatura média mensal dos modelos Eta-HadGEM2-ES, Eta-MIROC5 e Eta-CanESM2 na BHRJ sem correção, os dados mensais observados na estação meteorológica de Lavras e os dados simulados corrigidos. As projeções da precipitação total mensal e temperatura média mensal também são apresentadas nas Figuras 4 e 5, durante os três períodos dos cenários de emissão, RCP4.5 e RCP8.5 (2006-2040, 2041-2070 e 2071-2099).
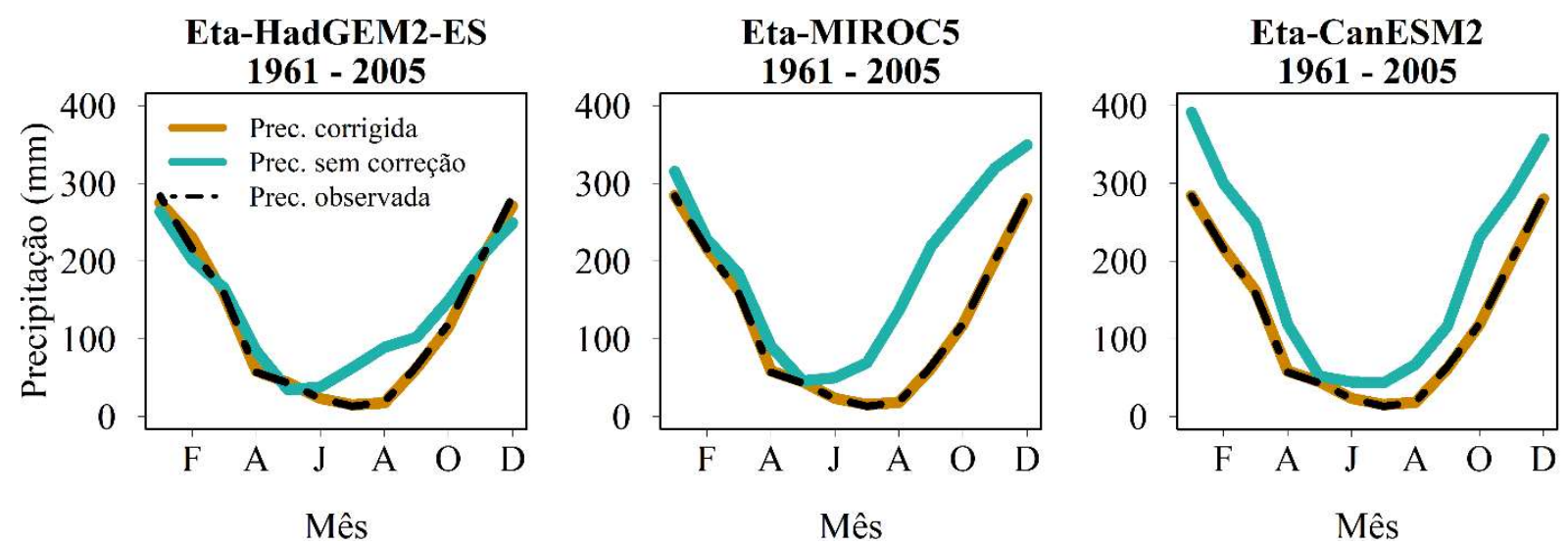

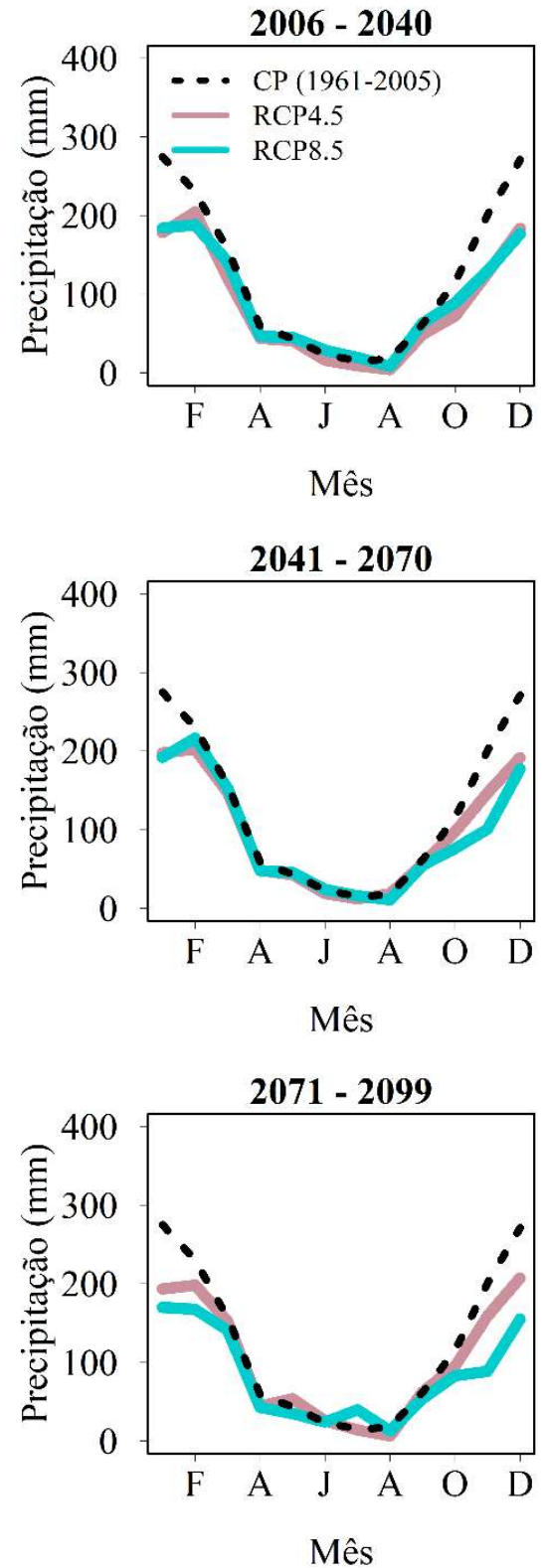
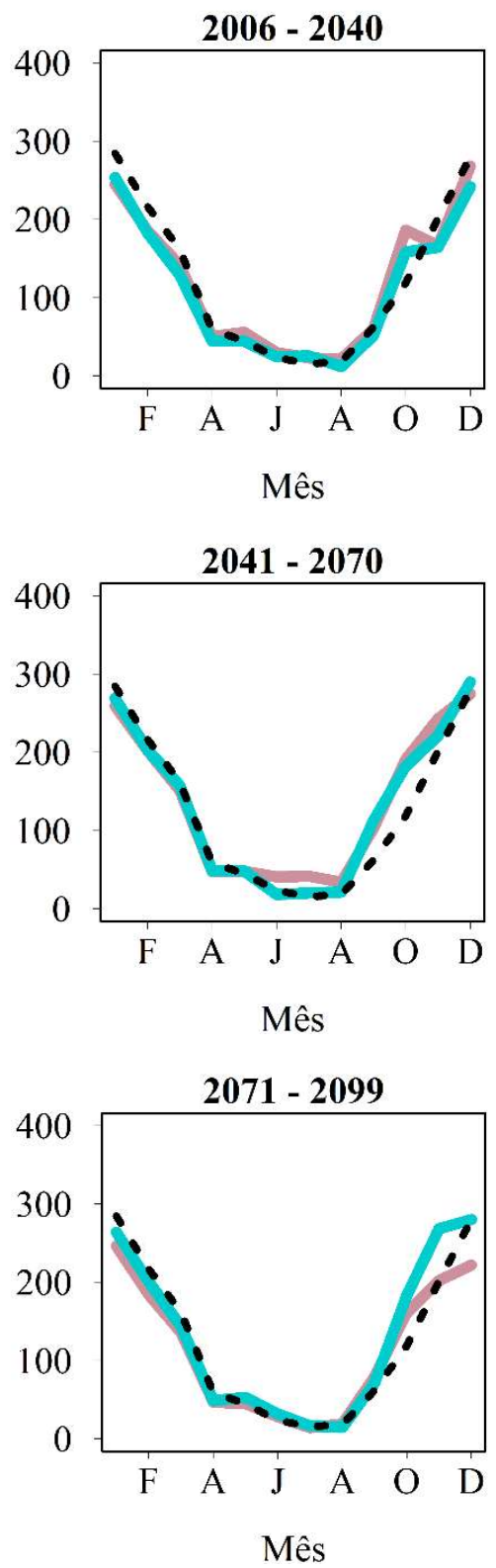
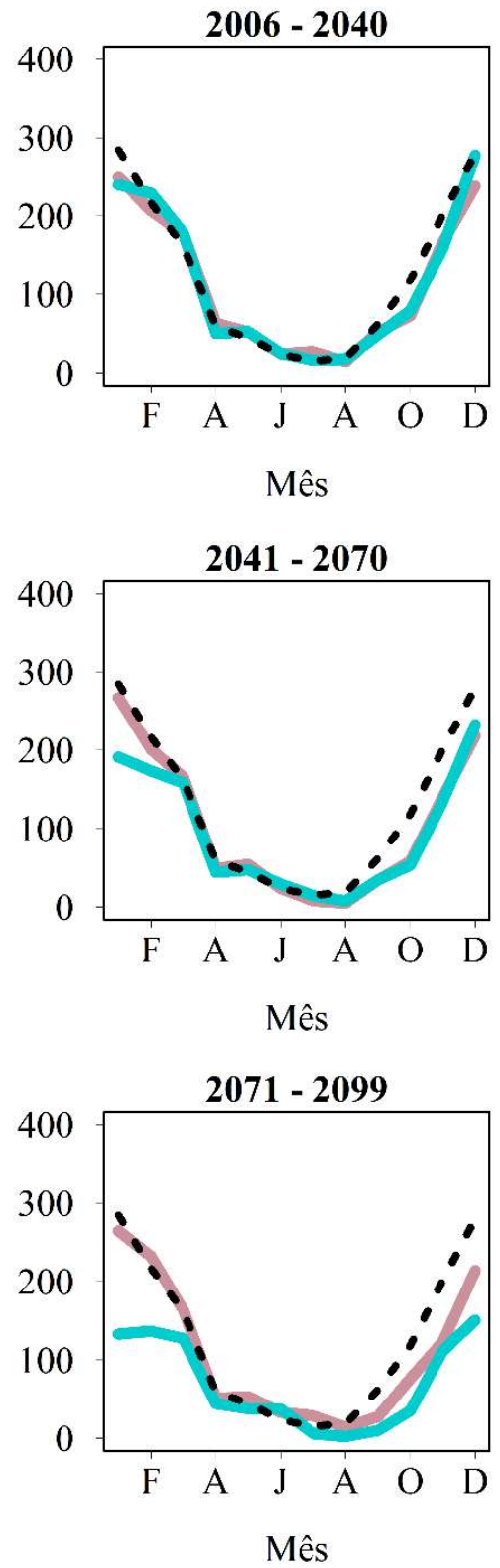

Figura 4: Precipitação total (Prec) mensal observada (Lavras - INMET), precipitação total mensal sem correção e corrigida (BHRJ) para o clima presente (CP) (1961-2005). Na sequência, precipitação mensal total corrigida para o clima presente e cenários RCP4.5 e RCP8.5 (2006-2040, 2041-2070 e 2071-2099).
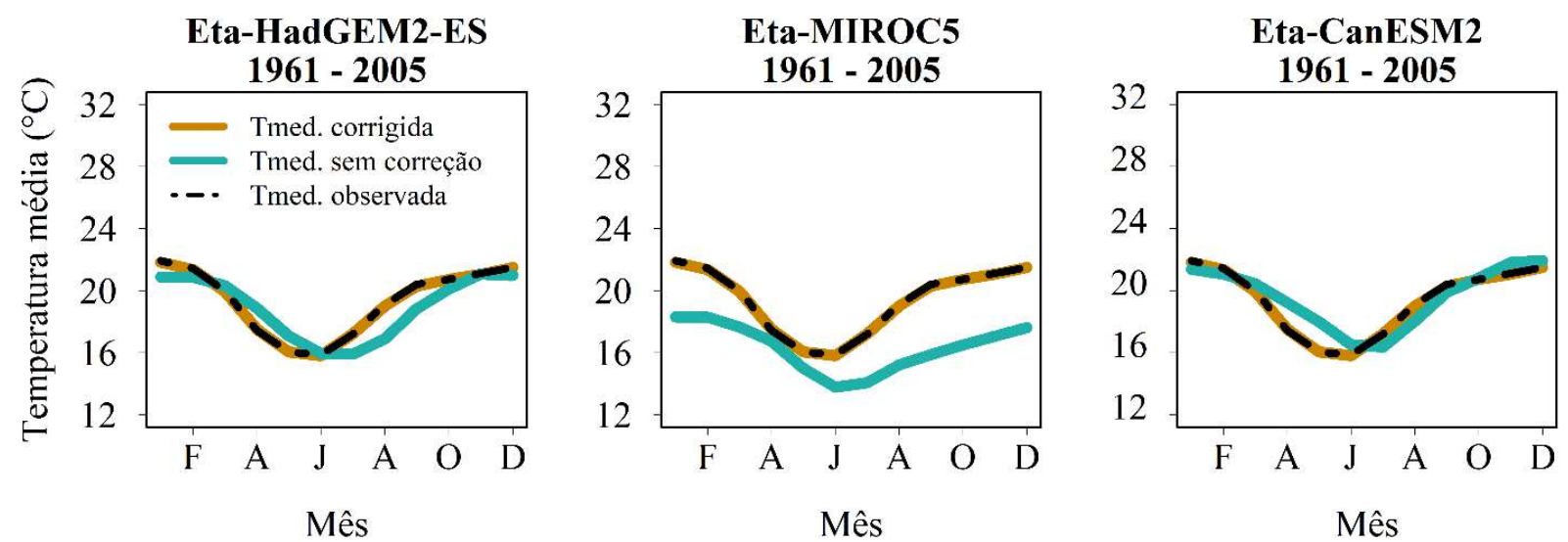

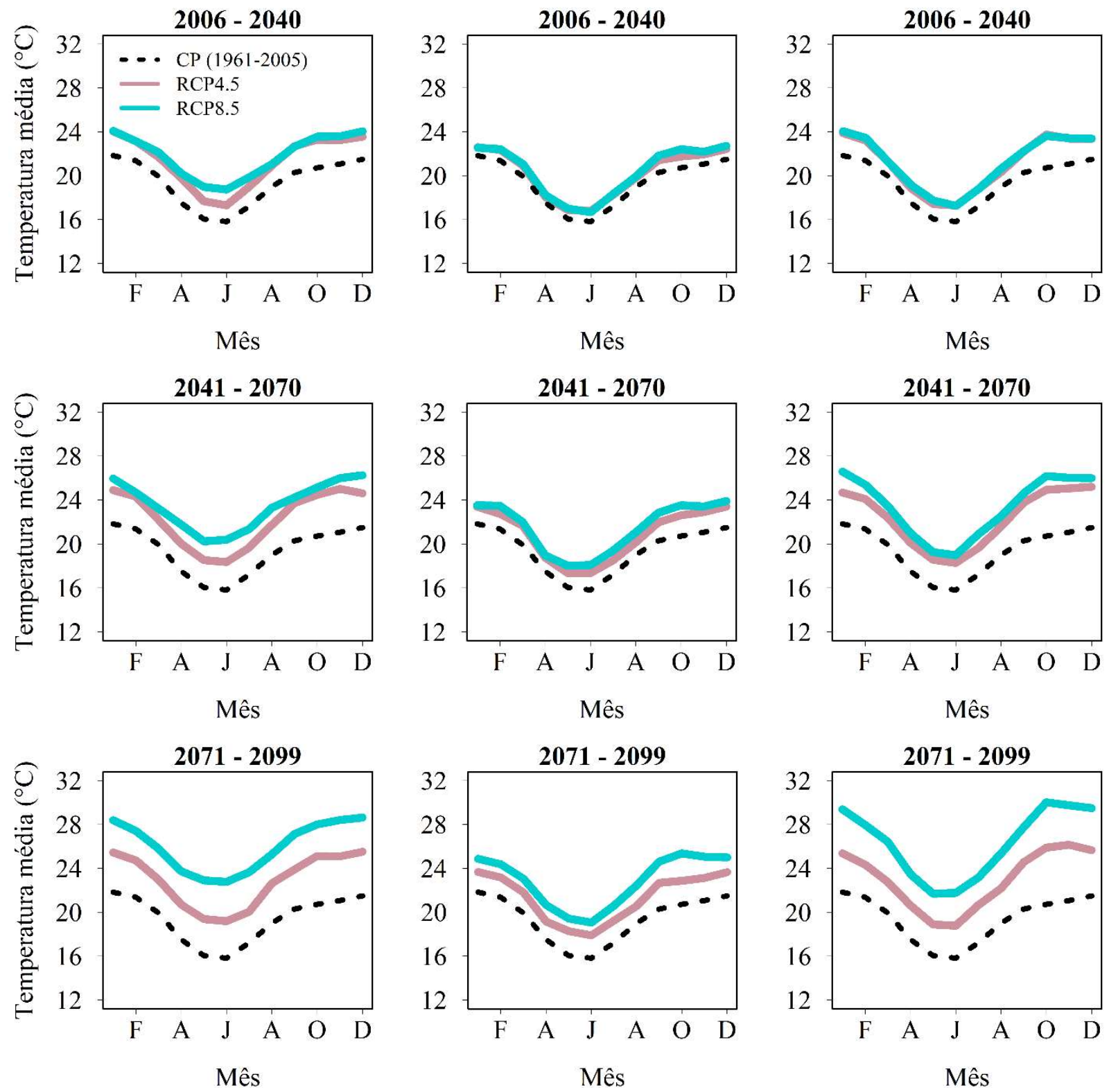

Figura 5: Temperatura média (Tmed) mensal observada (Lavras - INMET), temperatura média mensal sem correção e corrigida (BHRJ) para o clima presente (CP) (1961-2005). Na sequência, temperatura média mensal corrigida para o clima presente e cenários RCP4.5 e RCP8.5 (2006-2040, 2041-2070 e 2071-2099).

As Figuras 6 e 7 mostram o percentual da mudança na precipitação total mensal e temperatura média mensal durante os períodos 2006-2040, 2041-2070 e 2071-2099 (RCP4.5 e RCP8.5), quando comparado ao clima presente para os modelos Eta-HadGEM2-ES, Eta-MIROC5 e Eta-CanESM2.
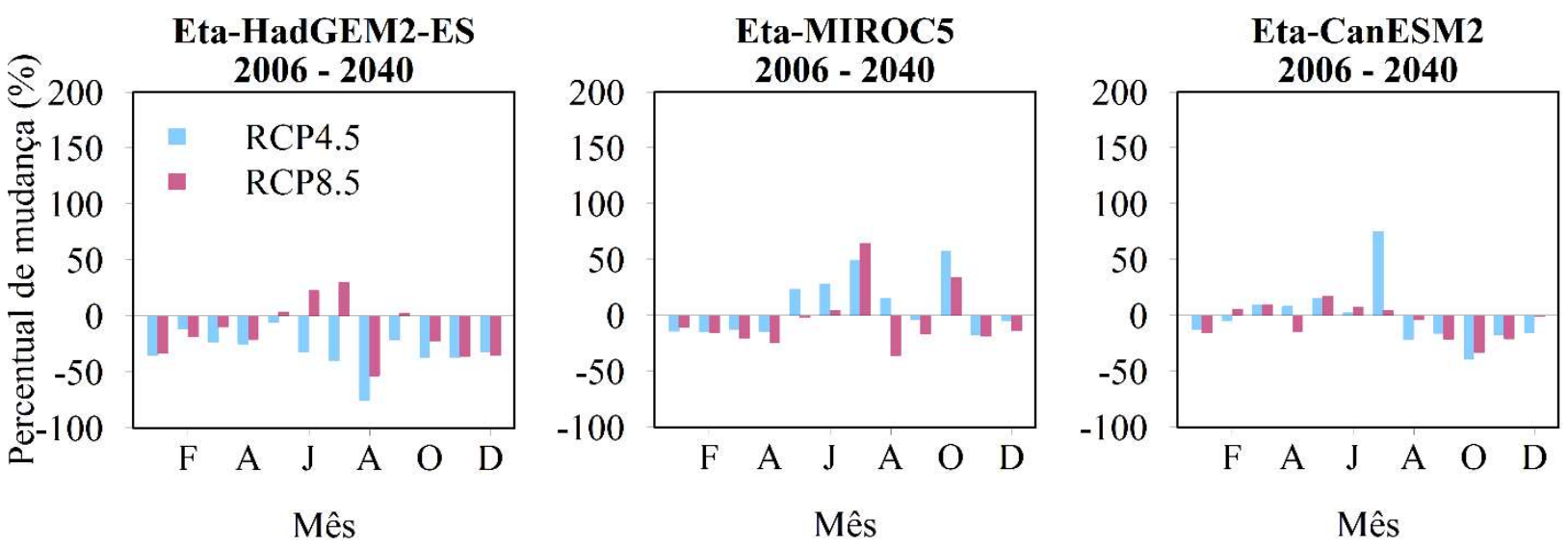

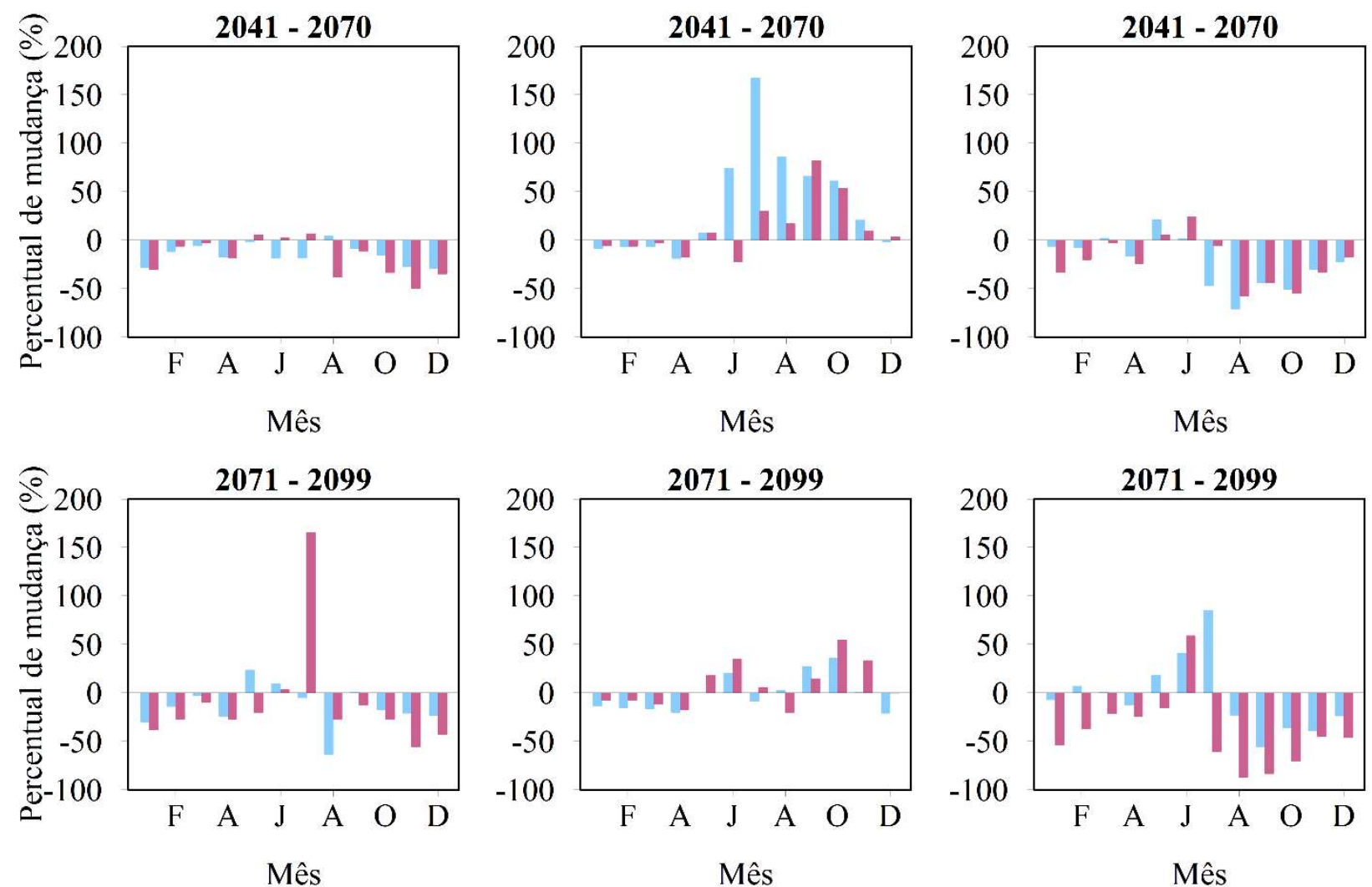

Figura 6: Percentual de mudança da precipitação total mensal no clima futuro (2006-2040, 2041-2070 e 2071-2099), sob os cenários RCP4.5 e RCP8.5, em relação ao clima presente (1961-2005) para todos os modelos climáticos.
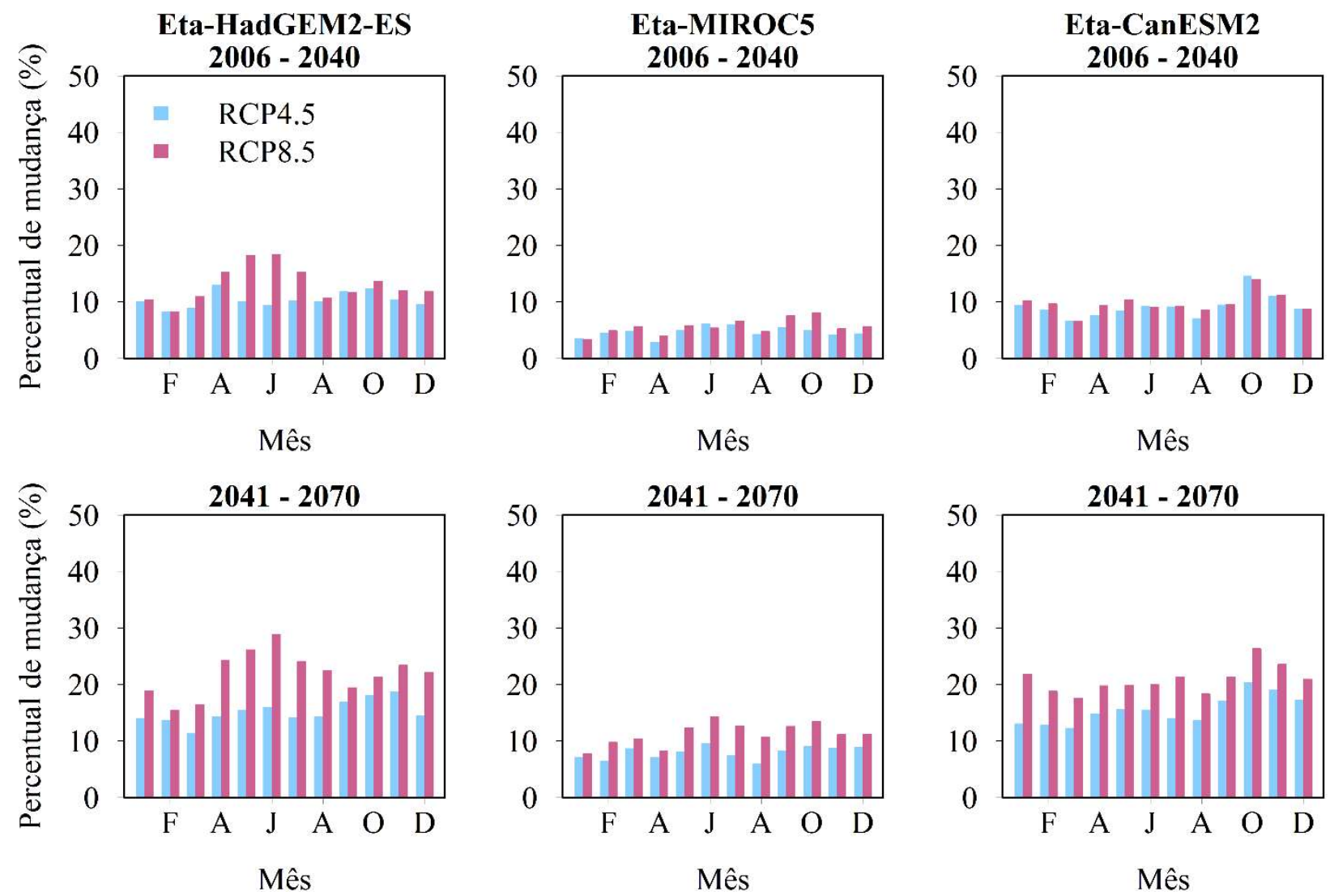

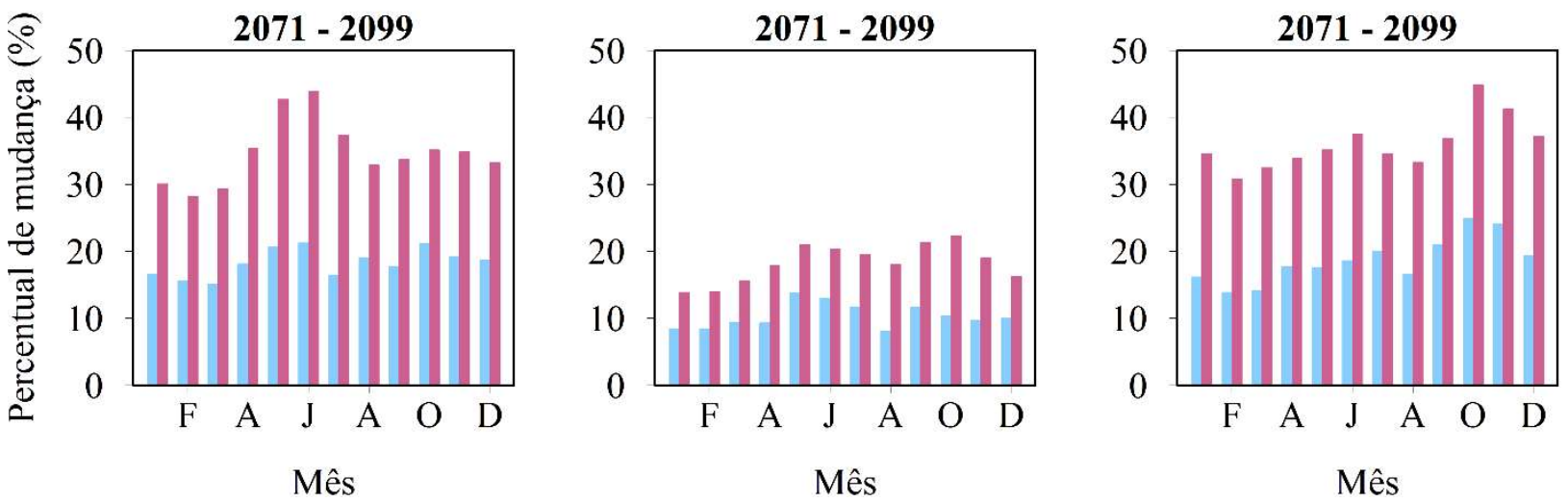

Figura 7: Percentual de mudança da temperatura média mensal no clima futuro (2006-2040, 2041-2070 e 2071-2099), sob os cenários RCP4.5 e RCP8.5, em relação ao clima presente (1961-2005) para todos os modelos climáticos.

A Tabela 2 mostra o percentual de mudança sazonal médio da precipitação total e da temperatura média no futuro (2006-2040, 2041-2070 e 2071-2099) em relação ao clima presente (1961-2005) na BHRJ. O percentual de mudança sazonal médio refere-se ao conjunto de modelos atmosféricos (multi-model ensemble mean) utilizados no presente estudo.

Tabela 2: Percentual da mudança da precipitação total e da temperatura média sazonal, projetado no futuro (20062040, 2041-2070 e 2071-2099) em relação ao clima presente (1961-2005) referentes a média do conjunto de modelos climáticos para a BHRJ.

\begin{tabular}{|c|c|c|c|c|c|c|}
\hline \multicolumn{7}{|c|}{ Percentual da mudança da precipitação total (\%) } \\
\hline \multirow[t]{2}{*}{ Estação } & \multicolumn{2}{|c|}{$2006-2040$} & \multicolumn{2}{|c|}{ 2041-2070 } & \multicolumn{2}{|c|}{ 2071-2099 } \\
\hline & RCP4.5 & RCP8.5 & RCP4.5 & RCP8.5 & RCP4.5 & RCP8.5 \\
\hline Verão & $-16,3$ & $-15,6$ & $-13,9$ & $-16,8$ & $-16,1$ & $-29,1$ \\
\hline Outono & $-5,8$ & $-7,4$ & $-4,4$ & $-4,9$ & $-5,4$ & $-14,8$ \\
\hline Inverno & $-1,2$ & 3,9 & 19,1 & $-4,8$ & 7,4 & 8,7 \\
\hline Primavera & $-16,6$ & $-17,3$ & $-6,2$ & $-14,9$ & $-13,6$ & $-20,6$ \\
\hline \multicolumn{7}{|c|}{ Temperatura média (\%) } \\
\hline \multirow[t]{2}{*}{ Estação } & \multicolumn{2}{|c|}{ 2006-2040 } & \multicolumn{2}{|c|}{ 2041-2070 } & \multicolumn{2}{|c|}{ 2071-2099 } \\
\hline & RCP4.5 & RCP8.5 & RCP4.5 & RCP8.5 & RCP4.5 & RCP8.5 \\
\hline Verão & 7,5 & 8,1 & 12,0 & 16,3 & 14,1 & 26,5 \\
\hline Outono & 7,5 & 9,5 & 11,9 & 17,1 & 15,0 & 29,1 \\
\hline Inverno & 7,9 & 9,7 & 12,2 & 19,1 & 16,0 & 30,7 \\
\hline Primavera & 9,4 & 10,4 & 15,2 & 19,2 & 17,8 & 32,2 \\
\hline
\end{tabular}

\section{DISCUSSÃO}

Comparando-se as projeções climáticas dos modelos atmosféricos (Eta-HadGEM2-ES, Eta-MIROC5 e Eta-CanESM2) para o clima presente (1961-2005) e as observações da estação meteorológica de Lavras para o mesmo período, verificou-se subestimativas e superestimativas dos dados meteorológicos, indicando a necessidade de realizar a correção de erros sistemáticos dessas projeções, tanto do clima presente quanto do clima futuro (2006-2040, 2041-2070 e 2071-2099). A correção foi realizada para a precipitação total diária e para a temperatura média diária, variáveis estas que são essenciais em estudos climáticos e hidrológicos, além de serem amplamente utilizadas para avaliar a tendência de mudanças climáticas (ASFAW et al., 2018).

Os resultados da correção de erros sistemáticos da precipitação total mensal e temperatura média mensal, projetados pelos três modelos, sugerem que foi possível capturar os padrões de variações mensal até o final do século, por meio dos cenários RCP4.5 e RCP8.5, quando comparados aos resultados do clima presente. Sendo assim, no período chuvoso os meses de outubro a março apresentam valores máximos 
mensais médios de precipitação total e temperatura média. Já no período seco, os meses de abril a setembro apresentam valores mínimos médios de precipitação total e temperatura média (Figuras 4 e 5).

Na Figura 6, os cenários climáticos futuros ao longo do século XXI resultaram em redução mensal de até $75,2 \%$ (RCP4.5, no mês de agosto, durante o período de 2006-2040), 35,6\% (RCP8.5, no mês de agosto, durante o período de 2006-2040) e 87,3\% (RCP8.5, no mês de agosto, durante o período de 2071-2099) e aumento mensal de até 165,4\% (RCP8.5, no mês de julho, durante o período 2071-2099), 167,2\% (RCP4.5, no mês de julho, durante o período 2041-2070) e 85,3\% (RCP4.5, no mês de julho, durante o período 20712099), com os modelos Eta-HadGEM2-ES, Eta-MIROC5 e Eta-CanESM2, respectivamente. Essas mudanças indicam redução mensal da precipitação total de até $16,1 \mathrm{~mm}$ (RCP4.5, no mês de agosto, durante o período de 2006-2040) e aumento mensal de até 26,0 mm (RCP4.5, no mês de julho, durante o período de 20412070), com as projeções dos modelos Eta-HadGEM2-ES e Eta-MIROC5.

Na Figura 7, existe um consenso geral de aumento de temperatura média projetada com os três modelos climáticos em todos os meses do ano. As mudanças mensais da temperatura são notavelmente maiores para os modelos Eta-HadGEM2-ES e Eta-CanESM2 do que para o Eta-MIROC5, principalmente no RCP8.5. Os maiores aumentos ocorrem no final do século XXI (2071-2099) para todos os modelos. Os cenários climáticos futuros ao longo do século resultaram em aumento mensal de até 43,9\% (RCP8.5, no mês de junho, durante o período 2071-2099), 22,4\% (RCP8.5, no mês de outubro, durante o período 2071-2099) e 44,8\% (RCP8.5, no mês de outubro, durante o período 2071-2099), com os modelos Eta-HadGEM2-ES, Eta-MIROC5 e Eta-CanESM2 respectivamente. Essas mudanças indicam aumento mensal da temperatura média de até 9,3 ${ }^{\circ} \mathrm{C}$ (em outubro), com as projeções dos modelos Eta-CanESM2, no cenário RCP8.5.

Quanto a Tabela 2, que mostra o percentual de mudança sazonal médio da precipitação total e da temperatura média no futuro (2006-2040, 2041-2070 e 2071-2099) em relação ao clima presente (19612005) na BHRJ, verificou-se que a redução da precipitação total sazonal média é evidente no clima futuro na maioria das estações do ano, com exceção do inverno, onde ocorrem aumentos nos períodos de 2006-2040 (RCP8.5), 2041-2070 (RCP4.5) e 2071-2099 (RCP4.5 e RCP8.5). Verificou-se maiores reduções da precipitação no verão (até $29,13 \%$ ) e na primavera (até $20,65 \%$ ), estações estas que concentram o período chuvoso da região onde a BHRJ está localizada. O modelo Eta-HadGEM2-ES mostrou uma redução de 16,5\% (outono, RCP4.5, 2041-2070), aproximando-se do percentual de redução do conjunto de modelos (outono, RCP4.5, 2041-2070), que é de $16,1 \%$.

A respeito da temperatura média sazonal, ainda na Tabela 2, observa-se concordância do conjunto de modelos climáticos, sendo possível verificar o aumento gradual ao longo do século (2006-2040, 20412070 e 2071-2099), nos RCP4.5 e RCP8.5, em todas as estações do ano. Na primavera, verificou-se os maiores aumentos (até 32,2\%) da temperatura média sazonal na BHRJ, sendo as maiores mudanças no período de 2071-2099, sob o RCP8.5.

Resultados semelhantes aos obtidos no presente estudo foram observados na região da bacia hidrográfica do Rio Grande em relação às projeções da precipitação total e da temperatura média. No que diz respeito à precipitação total da BHRJ, o modelo Eta-HadGEM2-ES apresentou um aumento das 
temperaturas médias sazonais acima de $6{ }^{\circ} \mathrm{C}$ (RCP8.5, 2071-2099), valor próximo ao encontrado por Alvarenga et al. (2018) com o modelo Eta-HadGEM2-ES, ao notar aumentos superiores a $5{ }^{\circ} \mathrm{C}$ nas projeções da temperatura em todas as estações do ano (RCP8.5, 2071-2099). A temperatura média da BHRJ apresentou aumento médio mensal de $2,8^{\circ} \mathrm{C}$ (RCP4.5) e 4,4 으 (RCP8.5) com o modelo Eta-HadGEM2-ES, resultados estes similares aos obtidos por Oliveira et al. (2017), que observou aumento médio mensal das temperaturas máximas e mínimas de, respectivamente, 3,1 e 0,5 으 (RCP4.5) e 5,4 e $1,7^{\circ} \mathrm{C}(\mathrm{RCP} 8.5)$. Sendo assim, ambas as pesquisas corroboram os resultados deste estudo.

Os resultados da precipitação média mensal (Figuras 4 e 6) quando comparados aos resultados obtidos por Mello et al. (2015), indicaram tendências hidrológicas distintas. É valido ressaltar que na pesquisa de Mello et al. (2015), o cenário climático avaliado é diferente deste estudo, sendo o cenário A1B (Quarto Relatório de Avaliação - AR4) (IPCC, 2007) utilizado. Mello et al. (2015) verificaram, para todas as bacias de cabeceira da Bacia Hidrográfica do Rio Grande, aumento da precipitação média mensal, com exceção dos meses de setembro e outubro, em todo o clima futuro (2011-2040, 2041-2070, 2071-2099). Além disso, não foi verificado aumento da precipitação média mensal no mês de novembro para o período 2011-2040. No presente estudo, as projeções também mostraram redução da precipitação mensal para os meses de setembro e outubro no futuro (2006-2040, 2041-2070, 2071-2099), exceto nas simulações do modelo EtaMIROC5. Essa redução pode indicar atraso no processo de início do ano hidrológico na região, e implica em um maior esgotamento do fluxo base nesses meses (MELLO et al., 2015; VIOLA et al., 2015).

\section{CONCLUSÕES}

Os cenários climáticos futuros ao longo do século XXI resultaram em redução da precipitação mensal de $87,3 \%$ (RCP8.5, no mês de agosto, durante o período de 2071-2099), com as projeções do modelo EtaHadGEM2-ES, o que implica numa redução de 16,1 mm em relação ao clima presente (1961-2005). O maior aumento da precipitação mensal observado foi de 167,2\% (RCP4.5, no mês de julho, durante o período 20412070) com as projeções do modelo Eta-MIROC5, sendo equivalente a $26,0 \mathrm{~mm}$ a mais quando comparado ao clima presente.

Os maiores aumentos mensais da temperatura média ocorrem no final do século XXI (2071-2099) para todos os modelos, com o RCP8.5. Destaca-se o aumento mensal de 44,8\% (RCP8.5, no mês de outubro, durante o período 2071-2099), com o modelo Eta-CanESM2, o que implica em $9,3{ }^{\circ} \mathrm{C}$ acima do que foi observado no clima presente.

A redução da precipitação total sazonal média é evidente no clima futuro na maioria das estações do ano, com exceção do inverno. Verificou-se maiores reduções da precipitação sazonal no verão (até 29,13\%) e na primavera (até $20,65 \%$ ), estações estas que concentram o período chuvoso da região onde a BHRJ está localizada. Quanto à temperatura média sazonal, observa-se concordância do conjunto de modelos climáticos, sendo possível verificar o aumento gradual ao longo do século (2006-2040, 2041-2070 e 20712099), nos RCP4.5 e RCP8.5, em todas as estações do ano.

Caso as projeções climáticas se concretizem até o final do século, é possível que haja queda ou, até 
mesmo, inviabilização da produtividade de pequenos agricultores que habitam a região da BHRJ, principalmente, de milho, visto que a safra no estado de Minas Gerais ocorre no período (outubro - janeiro) em que se observou elevada redução da precipitação ao longo das análises. Além disso, do ponto de vista do ciclo hidrológico, o constante aumento da temperatura ao longo do século XXI faz com que as taxas de evaporação também aumentem, elevando os níveis de vapor d'água na atmosfera e deixando a disponibilidade hídrica imprevisível para a região. Como consequência direta da instabilidade ocorrida no ciclo hidrológico, eventos extremos são esperados, podendo ocorrer chuvas torrenciais devastadoras ou eventos de seca mais graves, especialmente na estação chuvosa da região (verão).

AGRADECIMENTOS: os autores gostariam de agradecer a Coordenação de Aperfeiçoamento de Pessoal de Nível Superior (CAPES) e o Conselho Nacional de Desenvolvimento Científico e Tecnológico (CNPq) pelo financiamento dessa pesquisa.

\section{REFERÊNCIAS}

ALVARENGA, L. A.; MELLO, C. R.; COLOMBO, A.; CHOU, S. C.; CUARTAS, L. A.; VIOLA, M. R.. Impacts of Climate Change on the Hydrology of a Small Brazilian Headwater Catchment Using the Distributed Hydrology-Soil-Vegetation Model. American Journal of Climate Change, v.7, n.2, p.355-366, 2018. DOI: https://doi.org/10.4236/ajcc.2018.72021

ALVES, G. J.; MELLO, C. R.; BESKOW, S.; JUNQUEIRA, J. A.; NEARING, M. A.. Assessment of the soil conservation service-curve number method performance in a tropical oxisol watershed. Journal of Soil and Water Conservation, v.74, n.5, p.500-512, 2019. DOI:

https://doi.org/10.2489/jswc.74.5.500

AMORIM, P. B.; CHAFFE, P. B.. Towards a comprehensive characterization of evidence in synthesis assessments: the climate change impacts on the Brazilian water resources. Climatic Change, v.155, n.1, p.37-57, 2019. DOI: https://doi.org/10.1007/s10584-019-02430-9

ANDRADE, M. A.; MELLO, C. R.; BESKOW, S.. Hydrological simulation in a watershed with predominance of Oxisol in the upper Grande river region, MG - Brazil. Revista Brasileira de Engenharia Agricola e Ambiental, v.17, n.1, p.69-76, 2012. DOI: https://doi.org/10.1590/S1415$\underline{43662013000100010}$

ARORA, V. K.; SCINOCCA, J. F.; BOER, G. J.; CHRISTIAN, J. R.; DENMAN, K. L.; FLATO, G. M.; KHARIN, V. V.; LEE, W. G.; MERRYFIELD, W. J.. Carbon emission limits required to satisfy future representative concentration pathways of greenhouse gases. Geophysical Research Letters, v.38, n.5, p.3-8, 2011. DOI: https://doi.org/10.1029/2010GL046270

ASFAW, A.; SIMANE, B.; HASSEN, A.; BANTIDER, A.. Variability and time series trend analysis of rainfall and temperature in northcentral Ethiopia: A case study in Woleka sub-basin. Weather and Climate Extremes, v.19, p.29-41, 2018. DOI:

https://doi.org/https://doi.org/10.1016/i.wace.2017.12.002
BÁRDOSSY, A.; PEGRAM, G.. Downscaling precipitation using regional climate models and circulation patterns toward hydrology. Water Resources Research, v.47, n.4, p.1-18, 2011. DOI: https://doi.org/10.1029/2010WR009689

BESKOW, S.; MELLO, C. R.; NORTON, L. D.. Development, sensitivity and uncertainty analysis of LASH model. Scientia Agricola, v.68, n.3, p.265-274, 2011a. DOI: https://doi.org/10.1590/s0103-90162011000300001

BESKOW, S.; MELLO, C. R.; NORTON, L. D.; SILVA, A. M.. Performance of a distributed semi-conceptual hydrological model under tropical watershed conditions. Catena, v.86, n.3, p.160-171, 2011b. DOI:

https://doi.org/http://dx.doi.org/10.1016/j.catena.2011.03. $\underline{010}$

BLACK, T. L.. The new NMC mesoscale Eta Model: description and forecast examples. Weather \& Forecasting, v.9, n.2, p.265-278, 1994. DOI: https://doi.org/10.1175/15200434(1994)009<0265:TNNMEM>2.0.CO;2

CASAGRANDE, L.; TOMASELLA, J.; ALVALÁ, R. C. S.; BOTTINO, M. J.; CARAM, R. O.. Early flood warning in the Itajaí-Açu River basin using numerical weather forecasting and hydrological modeling. Natural Hazards, v.88, n.2, p.741757, 2017. DOI: https://doi.org/10.1007/s11069-017-2889-0

CAVALCANTI, I. F. A.; MARENGO, J. A.; SATYAMURTY, P.; NOBRE, C. A.; TROSNIKOV, I.; BONATTI, J. P.; MANZI, A. O.; TARASOVA, T.; PEZZI, L. P.; D'ALMEIDA, C.; SAMPAIO, G.; CASTRO, C. C.; SANCHES, M. B.; CAMARGO, H.. Global climatological features in a simulation using the CPTEC-COLA AGCM. Journal of Climate, v.15, n.21, p.2965-2988, 2002. DOI: https://doi.org/10.1175/15200442(2002)015<2965:GCFIAS>2.0.CO;2

CHOU, S. C.; LYRA, A.; MOURÃO, C.; DERECZYNSKI, C.; PILOTTO, I.; GOMES, J.; BUSTAMANTE, J.; TAVARES, P.; SILVA, A.; RODRIGUES, D.; CAMPOS, D.; CHAGAS, D.; SUEIRO, G.; SIQUEIRA, G.; MARENGO, J.. Assessment of Climate 
Change over South America under RCP 4.5 and 8.5 Downscaling Scenarios. American Journal of Climate Change, v.03, n.05, p.512-527, 2014a. DOI: https://doi.org/10.4236/ajcc.2014.35043

CHOU, S. C.; LYRA, A.; MOURÃO, C.; DERECZYNSKI, C.; PILOTTO, I.; GOMES, J.; BUSTAMANTE, J.; TAVARES, P.; SILVA, A.; RODRIGUES, D.; CAMPOS, D.; CHAGAS, D.; SUEIRO, G.; SIQUEIRA, G.; NOBRE, P.; MARENGO, J.. Evaluation of the Eta Simulations Nested in Three Global Climate Models. American Journal of Climate Change, v.03, n.05, p.438-454, 2014b. DOI: https://doi.org/10.4236/ajcc.2014.35039

CHYLEK, P.; LI, J.; DUBEY, M. K.; WANG, M.; LESINS, G.. Observed and model simulated 20th century Arctic temperature variability: Canadian Earth System Model CanESM2. Atmospheric Chemistry and Physics Discussions, v.11, n.8, p.22893-22907, 2011. DOI: https://doi.org/10.5194/acpd-11-22893-2011

COLLINS, W. J.; BELLOUIN, N.; DOUTRIAUX-BOUCHER, M.; GEDNEY, N.; HALLORAN, P.; HINTON, T.; HUGHES, J.; JONES, C. D.; JOSHI, M.; LIDDICOAT, S.; MARTIN, G.; O'CONNOR, F.; RAE, J.; SENIOR, C.; SITCH, S.; TOTTERDELL, I.; WILTSHIRE, A.; WOODWARD, S.. Development and evaluation of an EarthSystem model - HadGEM2. Geoscientific Model Development, v.4, n.4, p.997-1062, 2011. DOI: https://doi.org/10.5194/gmd-4-1051-2011

EK, M. B.; MITCHELL, K. E.; LIN, Y.; ROGERS, E.; GRUNMANN, P.; KOREN, V.; GAYNO, G.; TARPLEY, J. D.. Implementation of Noah land surface model advances in the National Centers for Environmental Prediction operational mesoscale Eta model. Journal of Geophysical Research D: Atmospheres, v.108, n.22, p.1-12, 2003. DOI: https://doi.org/10.1029/2002jd003296

FELS, S. B.; SCHWARZKOPF, M. D.. The simplified exchange approximation: A new method for radiative transfer calculations. Journal of the Atmospheric Sciences, v.32, n.7, p.1475-1488, 1975. DOI: https://doi.org/10.1175/15200469(1975)032<1475:TSEAAN>2.0.CO;2

GU, H.; YU, Z.; YANG, C.; JU, Q.. Projected changes in hydrological extremes in the Yangtze River basin with an ensemble of regional climate simulations. Water

(Switzerland), v.10, n.9, p.1-22, 2018. DOI: https://doi.org/10.3390/W10091279

IPCC. Intergovernmental Panel on Climate Change. Climate Change 2007: The Physical Science Basis, Working Group I Contribution of the Intergovernmental Panel on Climate Change. Cambridge: United Kingdom; New York: Cambridge University Press, 2007.

IPCC. Intergovernmental Panel on Climate Change. Climate Change 2013: The Physical Science Basis, Contribution of Working Group I of the Intergovernmental Panel on Climate Change. Cambridge: United Kingdom; New York: Cambridge University Press, 2013.

JANJIC, Z. I.. The step-mountain eta coordinate model: further developments of the convection, viscous sublayer, and turbulence closure schemes. Monthly Weather Review, v.122, n.5, p.927-945, 1994. DOI:

https://doi.org/10.1175/15200493(1994)122<0927:TSMECM>2.0.CO;2
JONES, C. D.; HUGHES, J. K.; BELLOUIN, N.; HARDIMAN, S. C.; JONES, G. S.; KNIGHT, J.; LIDDICOAT, S.; O'CONNOR, F. M.; ANDRES, R. J.; BELL, C.; BOO, K. O.; BOZZO, A.; BUTCHART, N.; CADULE, P.; CORBIN, K. D.; DOUTRIAUX-BOUCHER, M.; FRIEDLINGSTEIN, P.; GORNALL, J.; GRAY, L.; HALLORAN, P. R.; HURTT, G.; INGRAM, W. J.; LAMARQUE, J. F.; LAW, R. M.; MEINSHAUSEN, M.; OSPREY, S.; PALIN, E. J.; PARSONS CHINI, L.; RADDATZ, T.; SANDERSON, M. G.; SELLAR, A. A.; SCHURER, A.; VALDES, P.; WOOD, N.; WOODWARD, S.; YOSHIOKA, M.; ZERROUKAT, M.. The HadGEM2-ES implementation of CMIP5 centennial simulations. Geoscientific Model Development, v.4, n.3, p.543-570, 2011. DOI: https://doi.org/10.5194/gmd-4-543-2011

LACIS, A. A.; HANSEN, J. E.. A parameterization for the absorption of solar radiation in the earth's atmosphere. Journal of the Atmospheric Sciences, v.31, n.1, p.118-133, 1974. DOI: https://doi.org/10.1175/15200469(1974)031<0118:APFTAO>2.0.CO;2

LELIS, T. A.; CALIJURI, M. L.; FONSECA, A. S.; LIMA, D. C.. Impactos causados pelas mudanças climáticas nos processos erosivos de uma bacia hidrográfica: Simulação de cenários. Ambiente e Água - An Interdisciplinary Journal of Applied Science, v.6, n.2, p.282-294, 2011. DOI: https://doi.org/10.4136/ambi-agua. 200

LYRA, A.; TAVARES, P.; CHOU, S. C.; SUEIRO, G.; DERECZYNSKI, C.; SONDERMANN, M.; SILVA, A.; MARENGO, J.; GIAROLLA, A.. Climate change projections over three metropolitan regions in Southeast Brazil using the nonhydrostatic Eta regional climate model at $5-\mathrm{km}$ resolution. Theoretical and Applied Climatology, v.132, n.1-2, 2018. DOI: https://doi.org/10.1007/s00704-017-2067-z

MARTINS, M. A.. Estimativa da produtividade da cultura do milho no semiárido brasileiro, com base no modelo Aquacrop e previsão climática sazonal. São José dos Campos: Instituto Nacional de Pesquisas Espaciais, 2017.

MARTINS, M. A.; TOMASELLA, J.; DIAS, C. G.. Maize yield under a changing climate in the Brazilian Northeast: Impacts and adaptation. Agricultural Water Management, v.216, p.339-350, 2019. DOI: https://doi.org/https://doi.org/10.1016/j.agwat.2019.02.01 $\underline{1}$

MARTINS, M. A.; TOMASELLA, J.; RODRIGUEZ, D. A.; ALVALÁ, R. C. S.; GIAROLLA, A.; GAROFOLO, L. L.; JÚNIOR, J. L. S.; PAOLICCHI, L. T. L. C.; PINTO, G. L. N.. Improving drought management in the Brazilian semiarid through crop forecasting. Agricultural Systems, v.160, p.21-30, 2018. DOI: https://doi.org/https://doi.org/10.1016/j.agsy.2017.11.002

MELLO, C. R.; ÁVILA, L. F.; VIOLA, M. R.; CURI, N.; NORTON, L. D.. Assessing the climate change impacts on the rainfall erosivity throughout the twenty-first century in the Grande River Basin (GRB) headwaters, Southeastern Brazil. Environmental Earth Sciences, v.73, n.12, p.8683-8698, 2015. DOI: https://doi.org/10.1007/s12665-015-4033-3

MELLO, C. R.; NORTON, L. D.; CURI, N.; YANAGI, S. N. M.. Sea surface temperature (SST) and rainfall erosivity in the Upper Grande River Basin, southeast Brazil. Ciência e Agrotecnologia, v.36, n.1, p.53-59, 2012. DOI: https://doi.org/10.1590/s1413-70542012000100007 
MESINGER, F.; CHOU, S. C.; GOMES, J. L.; JOVIC, D.; BASTOS, P.; BUSTAMANTE, J. F.; LAZIC, L.; LYRA, A. A.; MORELLI, S.; RISTIC, I.; VELJOVIC, K.. An upgraded version of the Eta model. Meteorology and Atmospheric Physics, v.116, n.3-4, p.63-79, 2012. DOI: https://doi.org/10.1007/s00703-012$\underline{0182-z}$

OLIVEIRA, V. A.; MELLO, C. R.; VIOLA, M. R.; SRINIVASAN, R.. Assessment of climate change impacts on streamflow and hydropower potential in the headwater region of the Grande river basin, Southeastern Brazil. International Journal of Climatology, v.37, n.15, p.5005-5023, 2017. DOI: https://doi.org/10.1002/joc.5138

SALES, D. C.; COSTA, A. A.; SILVA, E. M.; VASCONCELOS JÚNIOR, F. C.; CAVALCANTE, A. M. B.; MEDEIROS, S. S.; MARIN, A. M. P.; GUIMARÃES, S. O.; ARAÚJO JUNIOR, L. M.; PEREIRA, J. M. R.. Projeções de mudanças na precipitação e temperatura no nordeste Brasileiro utilizando a técnica de downscaling dinâmico. Revista Brasileira de Meteorologia, v.30, n.4, p.435-456, 2015. DOI: https://doi.org/10.1590/0102-778620140075

SAMPAIO, G.; DIAS, P. L. S.. Evolução dos Modelos Climáticos e de Previsão de Tempo e Clima. Revista USP, n.103, p.4154, 2014. DOI: https://doi.org/10.11606/issn.23169036.v0i103p41-54

SANTOS, C. A. S.; ROCHA, F. A.; RAMOS, T. B.; ALVES, L. M.; MATEUS, M.; OLIVEIRA, R. P.; NEVES, R.. Using a hydrologic model to assess the performance of regional climate models in a semi-arid Watershed in Brazil. Water (Switzerland), v.11, n.1, p.1-17, 2019. DOI:

https://doi.org/10.3390/w11010170

SIQUEIRA JÚNIOR, J. L. S.; TOMASELLA, J.; RODRIGUEZ, D. A.. Impacts of future climatic and land cover changes on the hydrological regime of the Madeira River basin. Climatic Change, v.129, n.1-2, p.117-129, 2015. DOI: https://doi.org/10.1007/s10584-015-1338-x

TEUTSCHBEIN, C.; SEIBERT, J.. Bias correction of regional climate model simulations for hydrological climate-change impact studies: Review and evaluation of different methods. Journal of Hydrology, v.456, p.12-29, 2012. DOI: https://doi.org/10.1016/j.jhydrol.2012.05.052

VIOLA, M. R.; MELLO, C. R.; CHOU, S. C.; YANAGI, S. N.; GOMES, J. L.. Assessing climate change impacts on Upper Grande River Basin hydrology, Southeast Brazil.

International Journal of Climatology, v.35, n.6, p.1054-1068, 2015. DOI: https://doi.org/10.1002/joc.4038

WATANABE, M.; SUZUKI, T.; O'ISHI, R.; KOMURO, Y.; WATANABE, S.; EMORI, S.; TAKEMURA, T.; CHIKIRA, M.; OGURA, T.; SEKIGUCHI, M.; TAKATA, K.; YAMAZAKI, D.; YOKOHATA, T.; NOZAWA, T.; HASUMI, H.; TATEBE, H.; KIMOTO, M.. Improved climate simulation by MIROC5: Mean states, variability, and climate sensitivity. Journal of Climate, v.23, n.23, p.6312-6335, 2010. DOI: https://doi.org/10.1175/2010JCLI3679.1

ZHAO, Q.; CARR, F. H.. A prognostic cloud scheme for operational NWP models. Monthly Weather Review, v.125, n.8, p.1931-1953, 1997. DOI: https://doi.org/10.1175/15200493(1997)125<1931:APCSFO>2.0.CO;2

A CBPC - Companhia Brasileira de Produção Científica (CNPJ: 11.221.422/0001-03) detém os direitos materiais desta publicação. Os direitos referem-se à publicação do trabalho em qualquer parte do mundo, incluindo os direitos às renovaç̃oses, expansões e disseminações da contribuiç̃o, bem como outros direitos subsidiários. Todos os trabalhos publicados eletronicamente poderão posteriormente ser publicados em coletâneas impressas sob coordenação da Sustenere Publishing, da Companhia Brasileira de Produção Científica e seus parceiros autorizados. Os (as) autores (as) preservam os direitos autorais, mas não têm permissão para a publicação da contribuição em outro meio, impresso ou digital, em português ou em tradução. 